\title{
THE USE OF LEARNING PLATFORMS TO ORGANIZE LEARNING PLATFORMS TO ORGANISE LEARNING IN ENGLISH PRIMARY AND SECONDARY SCHOOLS
}

\author{
Carey Jewitt, Wilma Clark and Christina Hadjithoma-Garstka
}

This is a pre-print version of an article that appears in Learning, Media and Technology (2011) http://dx.doi.org/10.1080/17439884.2011.621955

\begin{abstract}
This paper reports on the use and potentials of Learning Platform (LP) technologies for organizing learning in English primary and secondary schools. It reports on the findings of qualitative research on the benefits of Learning Platforms (LPs) based on data from case studies in 12 'early adopting' English primary and secondary schools (2010, Jewitt et al). The paper reports findings on the potential of LPs to enhance student access to a broad range of learning resources, to increase opportunities for independent and personalised learning, to support opportunities for collaborative learning and to improve student processes of reflecting on and assessing their learning. The paper concludes by drawing out some of the pedagogic implications from these findings and a brief summary of the emerging conditions associated with the effective use of LPs to support and organize learning.
\end{abstract}

Key words: learning platform, assessment, independent learning, collaborative learning, personalised learning 


\section{THE USE OF LEARNING PLATFORMS TO ORGANIZE LEARNING PLATFORMS TO ORGANISE LEARNING IN ENGLISH PRIMARY AND SECONDARY SCHOOLS}

\section{INTRODUCTION}

There has been significant government and industry interest in the promotion of LPs. In this paper LP is used to encompass a range of technologies including virtual learning environments, management information systems, communications technologies and other information and resource sharing technologies. The character and form of these technologies as well as their use varies from school to school.

In some schools these technologies are integrated into shared online systems and environments that support teaching staff, students and, less often parents, to access learning resources, communicate and collaborate with each other, as well as monitor, assess and report on student progress.

This paper reports on the findings of a qualitative research project, funded by Becta in 2009-10 (Jewitt et al., 2010) that examined the potential benefits of using LP technologies for leadership and management, teaching, parental communication and involvement, and learning. It focuses on the research findings related to the organization of learning and forms of learning that are supported by LPs notably personalised and collaborative learning (rather than on learning per se). The aim of the project was to provide evidence to inform and support the effective use of LP technologies across schools (that is the use of the LP to realise the schools' goals within their a wider learning, teaching and management strategy). The project was informed by three main research objectives. First, to develop a detailed understanding of how LP technologies are being implemented, adopted and used within English primary and secondary schools; second, to provide robust evidence for the benefits that are being achieved through the effective use of LP technologies - in particular how LP technologies are fitting with schools' wider learning, teaching and management strategies; and third to develop understanding of the factors underpinning the effective use of LP technologies in schools. Findings on the positive potentials for learning realised through the use of LPs are presented here, alongside a discussion of the constraints and tensions experienced by the case study schools.

The potential advantages of LPs for learning and teaching have begun to be acknowledged within the education technology literature - especially in terms of the benefits associated with the use of virtual learning environments (see Weller 2007). Empirical evidence for the educational outcomes of LP technologies in schools is, however, limited, and most research to date has been small-scale non-peer reviewed action research. Evidence of benefits associated with LPs reported in social science research papers and peer-reviewed evaluation research include supporting innovative approaches to learning (Padmore et. al. 2006), student appreciation of immediate feedback provided by LP systems (Roth et. al. 2009), enhanced collaboration (that is where students draw on each others' resources and knowledge) between students (and the development of 'learning communities' and enhanced student levels of enjoyment and motivation (McCarthy et al. 2004, Valentine et al. 2005), supporting the development of bond between instructor-students (Rau et. al. 2008) and increased 'closeness' between parents and children (Kong \& Li 2008). 
The BESA survey of LP use in schools (Connor 2009) reported that the majority of secondary leaders to primary leaders anticipated LPs to provide some or an extensive improvement to teaching and learning in their schools. There are, however, a number of inconsistencies in the use of LP technology throughout the English school system. The Ofsted (2009) study of LP use in twenty-two educational institutions (including six primary and two secondary schools) suggested that although support for the technology existed from "enthusiastic staff and learners" the "use of VLEs to enhance learning was not widespread" (Ofsted 2009, p.4). The Harnessing Technology Report (Becta, 2009) reported a distinct divide between primary and secondary sectors - with 67 percent of secondary schools and 42 percent of primary schools currently using LP technology, with primary school leaders less likely to see the technology as a priority for their school (22 percent reported having no plans to introduce LP technology into their schools). In terms of the nature of school LP use, the Harnessing Technology school survey (Smith et al. 2008) reported the principal uses of LPs in many schools as a repository for documents for learning and teaching and, secondly, as a store for digital learning resources. Grant (2009) observed that the use of LPs within schools appears to conform to existing patterns of delivery and 'broadcast' of information and resources, rather than following more interactive patterns, that is they are mainly used to "upload content rather than interactive communication or learning" (Grant 2009, p.5).

\section{Research methods}

The research project took the same methodological approach to primary and secondary schools, although differences in and organizational approaches across the participating schools were accounted for when sampling the schools, and analyzing the data. It took a two-phase approach to addressing its aims and objectives.

\section{Phase One: knowledge mapping activities \& identification of case study schools}

Phase One of the project took place throughout September and October 2009 and sought to map existing evidence on the benefits that can be realised through the effective implementation and use of LPs and associated technologies, that is the use of the LP to realise the schools' goals within their a wider learning, teaching and management strategy. It involved a review of a wide range of literature and online networks alongside in-depth interviews with 15 key informants (policy makers, educational leaders, and LP industry). Findings from this phase informed the development of the fieldwork research instruments.

To select the case study schools the project team compiled an initial long list of 230 suitable primary and secondary schools across England. These included schools that were identified as having award-winning ICT provision and/or nationally recognised for their ICT use, as well as schools recommended by key informants. This list was reduced to 115 schools by removing schools with involvement in recent Becta research.

In order to gather local information on the short-listed schools a short email questionnaire was administered to these 115 schools supported by additional telephone or email contact. This information was used to select a sub-sample of 30 schools to fulfil the following section criteria: 
- A LP had been embedded in the school for more than one year;

- Clear evidence of identifiable school leadership around LP use;

- High level of visible online activity on the school LP;

- Clear focus on one or more key areas of teaching, learning, management, administration, and parent/home links.

From these thirty schools, a final sample of twelve schools (six primary and six secondary) was selected to offer a range of school types (i.e. urban/ rural, large/ small, single sex/ co-educational, different specialism) and LP applications to form the basis of the second phase of the project.

Phase Two: In depth case studies of twelve schools (October 2009 and February 2010). Each case study consisted of:

In-depth interviews conducted with school senior management and administration teams (SMTs) involved in the use of the LP in each school. These interviews provided a rich picture of the institution and organisational issues underlying the implementation and improvement of the managed learning system. Interviews focused on a range of areas including assessment management, monitoring student progress, reporting, curriculum planning, and communication.

Focus group interviews of between four to eight teachers conducted in each school to gain a sense of their use of LPs in the course of their practice. These interviews were used to explore issues raised by the school SMT, as well as identifying the use of the LP to support and extend teaching, planning, administration, and the creation/sharing of resources), and assessment.

Focus group interviews facilitated with four to six students from two year groups in each school. These interviews utilised student homework planners, images of LPs, and interaction with the school's LP using talk-aloud protocols to capture the student perspective. The students in each group reflected the range of ability groups within the year. Topics covered included learning materials and support, choice, personalisation, communication and collaboration.

Structured classroom observations of students' in-class use of LP technologies. The observations used a structured, observational grid to collect data on how the LP featured in the school, variation of use across subject areas, learning materials, and issues of personalisation (defined later in the paper), and motivation.

In-depth interviews conducted with parents/carers from each school, where appropriate. The first half of these interviews took the form of a 'talk aloud' observation of the parent's use of the LP. Here parents were asked to demonstrate how they used the LP on a computer equipped with screen-capture and voice-capture software. The second half of the interviews allowed parents to explore and expand upon wider issues relating to the LP.

All of these research activities resulted in a total of 277 respondents being interviewed across the twelve case-study schools (see Table 1). 


\begin{tabular}{llll}
\cline { 2 - 4 } & $\begin{array}{l}\text { Primary } \\
\text { schools } \\
(\mathrm{n}=6)\end{array}$ & $\begin{array}{l}\text { Secondary } \\
\text { schools } \\
(\mathrm{n}=6)\end{array}$ & Total \\
\hline Senior management & 24 & 11 & 35 \\
ICT co-ordinators & 6 & 11 & 17 \\
Teachers & 24 & 30 & 54 \\
Students & 95 & 49 & 144 \\
Parents/ carers & 14 & 4 & 18 \\
$\begin{array}{l}\text { Others (governors, library } \\
\text { managers, administrators) }\end{array}$ & 6 & 3 & 9 \\
\hline
\end{tabular}

Table 1: Number of interviewees across the twelve case study schools.

\section{Analysis}

Thematic and content analytical procedures were used to categorize and code the different data sets. The preliminary analysis of the case study observational and interview data was guided by a focus on the benefits of LPs in four areas of activity/ high level codes: parental involvement, learning, teaching, and management. The completed case study descriptions, literature review and a series of stakeholder interviews were used to generate a second level of thematic codes. This generated an initial set of 23 codes which were further refined through iterative analysis across the data set to produce a final set of twelve codes of the benefit of LPs: Enhancing the accessibility, quality, relevance and range of resources; Increased opportunities for collaborative learning; Increased opportunities for independent and personalised learning; Building the school civic identity and community; Enhancing digital literacies; Facilitating leadership and management of teaching; Improved management of student behaviour and attendance; Improving the processes of monitoring and assessing learning; Increased and improved organisation of information and communication; Making best use of teacher time; Parental involvement and supporting learning at home; and Supporting additional educational needs and inclusion. This paper focuses on the first three of these codes related to the organisation of learning. Each code was further defined by the project team through the second stage of preliminary analysis to generate a third level of descriptive sub-codes, for instance increased opportunities for independent learning included sub-codes related to the degree of student choice, student autonomy, ownership, self-directed working, student confidence, and ICT skills. The third-level descriptive sub codes for each of the areas of learning discussed in this paper are provided under the relevant sections discussing each theme later in the paper.

These codes were applied qualitatively to the dataset to look at patterns of interaction across the different benefits in each case study, rather than to quantify the data. Thematic analysis enabled the data from the different sets to be combined to produce a coherent case study report on each school. These were reviewed and coded thematically by the project team. From this basis the data was selectively coded in terms of categories identified with the initial code list directly related to the aims of the study. The interview data were thematically analyzed via the N*VIVO software package.

A constant comparison technique was used to analyze the dataset that was generated from these interviews. This first involved reading all the interview transcripts to gain an 
overall sense of the data. A sample of the dataset was then read again and 'open-coded' until, in the opinion of the researchers, analysis had reached theoretical saturation. From this basis the whole dataset were then coded selectively in terms of categories identified with the initial code list directly related to the aims of the study. Thematic analysis enabled the data from the different data sets to be combined to produce a coherent variety of influences and factors underlying the use of LP technologies across the school.

\section{Findings: The uses of LPs for organising learning}

This paper presents and discusses the project findings relevant to the use and potentials of LPs for organising learning with a focus on four themes that emerged from the data:

- learning resources;

- opportunities for independent and personalised learning;

- opportunities for collaborative learning and interaction;

- processes of monitoring and assessing for learning and teaching.

Each of these themes is now discussed drawing on the case study data. It is important to note that the findings are from case study schools that were considered advanced in their use of LPs and where this technology was firmly embedded across the school. As shown by the statistics on schools uses of LPs (reported in the introduction) they are not typical of the majority of schools.

\section{Learning resources}

Categories concerned with learning resources that emerged from the data analysis included the range and quality of learning resources they had access to, the organisation of resources, the source of resources, for example, teacher-made, student-made or commercial resources, the sharing of resources, the adaption of resources to the local context, the role of resources in professional development, the role of resources in the surveillance of teachers and the involvement of students and parents, as well as student access and use of learning resources at home and in the classroom.

\section{Enhancing the range of resources}

School leaders, teachers and students viewed their LPs as enhancing the range and quality of learning resources they had access to. Teachers used the LP as a 'one-stop shop' to easily gather, organize and manage learning resources (e.g. folderized resource bank/repository). Online education content services, recommended links and downloadable resources provided via some LP providers gave teachers access to a wide range of appropriate teaching materials in addition to their own use of the Internet. The LP also provided a means to manage, access and use multiple resources within lessons, for instance, for managing multiple websites, audiovisual resources and Geographical Information System (GIS) simulators in the geography classroom. The LP also provided teachers with links to software applications for creating online materials. 


\section{Adapting and sharing resources}

Teachers in all the schools were encouraged to share resources and to collaborate at departmental or school level, to seek peer review and feedback, and to get ideas from each others' practice. The collaborative character of teacher resources on the LP was commented on as useful by all, particularly newly qualified teachers, who said it helped them to get ideas for their teaching and to better understand the possibilities for teaching as well as providing continuity when supply teachers were used. It also provided a route to manageable and relevant access to student content for teachers and students in the form of e-portfolios for example. Teachers reported benefits realised by the visibility and 'public' character of the LP in relation to learning resources including increased collaboration, possibilities for re-cycling and adapting colleagues' resources, a stronger sense of accountability, and a higher quality of resource development (in direct response to their visibility). However, some teachers also reported some negative aspects of this visibility in particular that it enabled a stronger managerial gaze on the work of teachers that may reduce innovation and risk taking.

\section{Student access to a range of resources}

The LP offered the students opportunities to access, select, use and manage learning resources at school or home. In the case study schools students could access a range of interactive and audiovisual materials through the LP including discussion forums, blogs and other collaborative applications, video clips, podcasts, photographs, quizzes, games and online tests. The LP also provided links relevant to project work and revision selected and approved by teachers. In all the case study schools the LP was actively used to scaffold and structure learning as fun, engaging and motivating with a focus on imaginative, creative and inclusive resources. Resources created by staff often sparked students' imagination and interest. As one Secondary school teacher noted:

'We've had science departments that are videoing their own experiments, so that children can see an experiment that they've actually been part of. They can see it now either by going on to YouTube or logging on to our Extranet, ... getting children involved in that creative procedure as well. So we've had girls doing sound recording, girls doing videoing, girls doing the actual commentary, girls doing the experiment itself. You involve them in a process like that and it boosts their interest.'

As one teacher commented:

'I think that they [parents] can see the real impact when they hear their child's voice on the video or they see them, they can link a bit more to it...it's just an easier way to understand...it just hits them straightaway, that's what they've been learning. And it's a good conversation topic and might it engage conversation and take learning further at home also than maybe a piece of writing would. But they've [writing and video] each got their place and importance in learning.'

\section{Student-made resources}


Some schools were encouraging students and parents to create their own content, allowing the dynamic creation and recreation of learning resources rather than the LP being used as a static digital 'drop box' or repository. LPs were being used to make learning resources more relevant to fit the specific needs of their class or students and sharing of student-generated content in a range of languages was more easily supported. Students were encouraged to generate resources to be shared with the school community via the LP including games design, and book reviews. The LP provided a space for students to publish and showcase their resources, and allowed students to take ownership of the resources and the LP more generally.

The potential of LPs to support innovative approaches to learning is noted in other studies (Padmore et. al. 2006). Some teachers (and students) reported that caution still rules too many decisions notably with respect to negative perceptions of social networking sites and this resulted in some useful sites and applications (e.g. Twitter and YouTube) being censored for fear of scandal or danger. Schools had also had to address parental perceptions of such sites and concerns about e-safety when using the LP and Web 2.0 applications.

'My only concerns on that are, I mean, if you're going to put photos or videos on an open website, you've got to cover it with parental consent' [Parent]

The case study schools had all worked with parents to allay concerns, and to educate students on e-safety. However, most of the schools were at an early stage of parental involvement and engagement and this continued to be a factor in the development of the LP.

\section{Opportunities for independent and personalised learning}

The main categories that emerged from the data in relation to student opportunities for independent and personalised learning included the design and organization of learning environments, the range of resources and the degree of student choice and autonomy supported by the LP, ownership, opportunities for self-directed working, moving beyond classroom-focused learning, student confidence and ICT skills, parental support and involvement with learning.

In all of the case study schools the LP was used to provide students with access to activities designed to supplement and support their classroom learning. Teachers sometimes set independent activities on the LP and made use of discussion forums, blogs and other collaborative applications. Others posted homework tasks for a whole week or month through the LP so that students could work through homework as they wished. Students developed and used revision and quiz materials on the LP .

All of the 12 case study schools had developed their use of LPs with the explicit aim of increasing student opportunities for independent and personalised learning (that is an approach to learning in which all pupils are able to progress, achieve and participate in different ways and at their own pace). They had achieved this by designing open and safe spaces on the LP for classes and subject areas and the provision of a range of resources. This increased student choice and autonomy regarding learning resources, and enabled them to select those that best suited their 
interests. Students spoke of taking ownership of and becoming more engaged in learning activities.

'You can just go on there and do it yourself. ... So then you're learning all yourself, without your teacher's help.'

(Year 4 student)

Across the case studies LPs were considered by teachers and students to support independent learning through enhanced student motivation, increased enjoyment and enthusiasm for topics, more opportunities for reflection and self-directed working including revision and preparation for examinations through the student-driven use of revision and quiz materials.

The case study schools worked to make homework tasks 'transparent' to parents, supplying them with prompts to support their child's engagement with set homework tasks and information to give parents a clear focus for schoolwork with their children. Some schools regularly sent digital messages via the LP to parents, for example, with details of homework tasks. Some Primary schools provided access to educational games specifically for parents to play with their child at home.

The use of the LP as the main space for independent learning is on the one hand a benefit for learning, and on the other shot through with tensions related to equity, relations between home and school, parental involvement with their child's learning, and access to technology in the home.

'Are we going to work on the basis that we're going to exclude 10\% of the school population? I've had comments from students saying, for whatever reason, I don't have access at home at the present time, I am unable to get the material that I need, so I think there is an equal opportunities issue.' (Teacher)

'Yes [I have got a computer at home], but I can't use it because of my sister, she also goes to college and she's got to do her homework.'

(Year 6 student)

Further, teachers commented that even when students do have access to equipment their lack the confidence and low literacy and ICT skills and without parental support for learning at home often found it difficult to navigate the LP interface.

'It could be a bit wordy for the lower abilities ... there are a lot of words and they click, they click and if they can't read very well that's hard.'

(Teacher)

'Some don't like the computer because they don't know what to do, and they don't know what the computer is like, and they don't have them at home and they won't know anything.'

(Year 2 Student)

Some teachers commented that student lack of access to the Internet in the home presented an ethical barrier to using the LP to set digital homework or extended 
independent learning. Others considered the school computer facilities ensured all students had access to the Internet and did not view access in the home as a barrier to setting digital work to extend independent learning.

\section{Increased opportunities for collaborative learning and interaction}

The main categories emerging from the data with respect to using LPs to increase opportunities for collaborative learning and interaction were the design of digital spaces for students to communicate, peer focused activities, the use of digital technologies to support collaborative practices and projects, as well as interaction between schools and teachers, the benefits of the sense of communicational distance afforded by LPs (i.e. the LP created a sense of a physical and emotional distance between students working online that students and teachers considered supported critical engagement), ideas of belonging and community.

The case study schools had developed their use of LPs to increase opportunities for collaborative learning and interaction. In all of the schools the LP was used as a space for students to share ideas and collaborate on projects, and to support collaborative learning and interaction between schools, and teachers. Although the extent to which students made use of these spaces varied across the schools and subject areas. Teachers and students reported that the LP supported increased student peer interaction. The digital tools facilitated by LPs, including blogs, wikis, and discussion boards were marshalled to provide a collaborative environment which teachers and students reported enlivened and enriched the learning process and created a range of productive social contexts for learning.

Collaboration took place within individual schools, and also across different schools. Students were provided a range of opportunities to engage with other students across different schools - especially between existing clusters of schools. Students in one primary school cluster, for instance, had worked on a never-ending story using a Wiki to focus on the cluster theme on writing. Another school had taken part in audio broadcasting to support a range of cross-school collaborations on writing. Students had been enabled to learn from each other, to amend, and improve their work through collaboration using digital applications on the LP . For instance, Wallwisher (an online notice board maker) had been used to generate debate on a topic, and a digital presentation developed and uploaded onto the LP to share, while another group had collaborated to make a video. As one Year 4 student commented:

'[working together] you don't learn exactly what you know, you can learn what your friend knows as well.'

Teachers reported that student use of blogs and discussion boards on the LP had provided students with more opportunities to develop their communicational skills and learned how to discuss, question, argue, and reason with one another in ways that had developed their potential to identify choices and hone their ideas. Teachers commented that the sense of distance afforded by digital online communication enabled interactions between students to be less emotional or personal which in turn had helped to support critique and difficult commentaries that face-to-face classroom interaction could not support so easily. Students and teachers noted that this contributed to developing a feeling of belonging to a learning community (either at 
community, school or class level). This echoes research that suggests enhanced collaboration between students can contribute to a more developed learning community (McCarthy et al. 2004:180).

The use of collaborative digital applications such as Wikis need, however, to be understood in the context of the school so that their collaborative affordances are not over-ridden by the social affordances of the context (Grant, 2006).

\section{Improved processes of monitoring and assessing for learning}

The main categories that emerged from the data with respect to the use of LPs and opportunities for monitoring and assessment concerned digital forms of teacher feedback, new forms of recording feedback, and the use digital technologies (e.g. video) to support student critical reflection, automated online feedback, and the visibility of grades over time to support self-review, and less positively a sense of surveillance for students and teachers.

The schools used the LP to create opportunities for self and peer review and to support a range of forms of assessment including the provision of teacher feedback in the form of track changes, the review of video recordings of classroom activity, the use of audio files in language lessons and for the assessment of speaking and listening, as well as automated feedback via quizzes. For example, students in one school had access to recordings uploaded to the LP of them talking in French which enabled them to listen to themselves speak and hear their accent. Other schools provided students with instant feedback, for example through the use of auto-scoring computer quizzes or teacher online feedback. Most of the schools provided students with some form of access to archives of their work on the LP. This supported students to see, assess, and value their progress over time and set their learning goals, it made their learning visible to them. As one Year 10 Student said:

"One thing I really like which I found especially nice, on it [LP] you can access all your different lessons... so you can literally click on each individual bit and you can go on classes from this year and classes from last year, so you can look at stuff you've done over time... "

Students in some schools were provided with data on the LP to enable them to review their targets, and find out what they need to focus on. For example, students in one school were ranked using a traffic light system in relation to their targets across the school year. Students and teachers were further supported in some schools to easily exchange messages enabling students to explain how they did their work to the teacher, using commentary boxes and audio notes, assessing their own work and difficulties. In some Primary schools important features of classroom assessment were made more permanent and shareable using the facilities of the LP . For example, the creation of permanent records of achievement or 'praise pod casts' took momentary comments from teachers and recorded them into an audio file for students to revisit and share with their family. This serves to open up a dialogue between student and teacher (and parent) around specific homework tasks. Other research suggests that this can support the development of a positive bond between instructor-students (Rau et. al. 2008). 


\section{Pedagogic implications and emerging conditions for the effective use of LPs to support learning}

Overall the analysis presented in this paper has shown that when used effectively LPs have the potential to support learning in primary and secondary schools of different sizes and the home in a number of significant ways. Notably giving students access to a broad range of learning resource, supporting opportunities for independent and personalised learning, facilitating student collaboration, and encouraging student reflection and self-assessment. Here we draw out some of the pedagogic implications of the findings.

With respect to resources the research findings indicate that the pedagogic benefits of LPs may be enhanced in both primary and secondary schools by 1) a clear shared vision of the purpose of the LP in relation to learning in school and at home and the links between the two; 2) ensuring a wide range of appropriate and safe resources and applications are made available to students that make full use of the different media and modes supported by digital technologies; 3) designing the LP to be a 'one-stop shop' that gives thematic structure to resources, gathers together, organizes and manages resources in a coherent way; 4) supporting teachers to adapt, recycle, and share existing resources; 5) fostering a collaborative risk taking environment in which teachers can share ideas and problem solve; and 6) providing staff training and support focused on both the technological features and pedagogic uses of a range of applications such as blogs, digital video, and podcasts in the design of learning resources.

All of the schools used the LP to generate opportunities for independent learning in the home and to a lesser extent the school (although some were more technologically and pedagogically innovative). Opportunities for independent and personalised learning can, the research findings indicate, be supported by the LP by 1) increased student choice and autonomy (e.g. regarding learning resources); 2) setting tasks and activities with open aspects; 3 ) ensuring access to student-driven time and activities; 4) the development of self-directed spaces on the LPs (e.g. blogs, forums); 5) the provision of permanent spaces on the LP for individual students to archive their work across their school life and that can be personalised; 6) ensuring access to educational games linked to learning outcomes; 7) reviewing options for supporting student access to technology at home and school; and 8) supplying parents with prompts to support young children's learning.

The research findings show that opportunities for collaborative learning and interaction can be supported by the use of LPs using many different media, over different time-spans. Collaboration can be organized across locations, including across year groups, schools, subjects, or be project-based collaborations. This appears to be most effective when the social and cultural practices of school (whether primary or secondary) and the technology are explored and e-safety and monitoring issues have been considered.

The research findings suggest that the potential of LPs to improve processes of monitoring and assessing for learning may be harnessed to useful pedagogic effect by 1) creating regular opportunities for self and peer review; 2) the use of digital technologies to support a range of innovative forms of assessment (e.g. praise pod 
casts); 3) providing students with materials over time to allow them to review their own work and progress; 4) creating opportunities for online dialogue between students, teachers and parents; and 5) being aware of the potential for permanent digital records to follow students in positive and negative ways.

The research reported in this paper is of course limited by its focus of the research on the benefits of LPs and a sample of schools identified as making good use of LPs for teaching, learning, and management. Nonetheless this paper highlights some of the potential benefits that could be realised through LPs and as such provides a rationale and starting point for those schools who wish to explore how and why they might want to make use of their LP to support the organisation of learning.

\section{References}

Becta (2007) 'Impact study of e-portfolios on learning' Coventry, Becta.

Becta (2009) 'Harnessing technology for next generation learning children, schools and families, summary report' Coventry, Becta

Connor, R. (2009) 'School learning platform review' London, BESA [British Educational Suppliers' Association]

Lewin, C. and Luckin, R. (In press) 'Technology to support parental engagement in elementary education: Lessons learned from the UK' in Computers \& Education.

Grant, L. (2009) 'Children's role in home-school relationships and the role of digital technologies' Bristol, Futurelab

Grant, L. (2006) Using wikis in schools: a case study, Bristol: Future Lab.

http://www2.futurelab.org.uk/resources/publications-reports-articles/discussion-

papers/Discussion-Paper258 (accessed 21.03.11)

Kong, S. and Li, K. (2009) 'Collaboration between school and parents to foster information literacy: Learning in the information society' Computers \& Education 52, pp.275-282

Jewitt, C., Hadjithoma-Garstka, C., Clark. W, Banaji, S. and Selwyn, N. (2010) School use of Learning Platforms and associated technologies: final project report, Coventy, Becta.

McCarthy, Bligh, Jennings and Tangney (2005) 'Virtual Collaborative Learning Environments for Music: Networked DrumSteps' Computers and Education, 44, 2, pp.173-195.

Padmore, M., Hall, L., Hogg, R. and Paley, G. (2006) 'Reviewing the potential of Virtual Learning Environments in Schools'

[http://osiris.sunderland.ac.uk/ cs0lha/Publications/2006/padmore-hall-hoggpaley.pdf].

Ofsted (2009) 'Virtual learning environments: an evaluation of their development in a sample of educational settings' London, HMI.

Rau, P., Gao, Q. and Wu, L. (2008) 'Using mobile communication technology in high school education: Motivation, pressure and learning performance' Computers and Education, 50 pp.1-22.

Roth, V., Ivanchenko, V. and Record, N. (2009) 'Evaluating student response to WeBWorK, a web -based homework delivery and grading system' Computers and Education, 50, pp.1462-1482. 
Smith, P., Rudd, P. and Coghlan, M. (2008) 'Harnessing Technology: Schools Survey 2008' Coventry: Becta

Valentine, G., Marsh, J. and Pattie, C. (2005) Children and Young People's Home Use of ICT for Educational Purposes: The Impact on Attainment at Key Stages 14. London. DfES.

Weller, M. (2007) 'Virtual learning environments' London, Routledge 